Ind. Health, 1967, 5, 171.

\title{
EFFECT OF PHENYLHYDRAZINE ON THE OXIDATION OF OXYHAEMOGLOBIN BY SODIUM NITRITE
}

\author{
Toshio KAKIZAKI, Mitsuo SATO, Hiroshi TSURUTA \\ and Hiromichi HASEGAWA
}

National Institute of Industrial Health, Kizuki-Sumiyoshi, Kawasaki

(Received January 9,1967)

\begin{abstract}
In the previous papers, the oxidation mechanism of oxyhaemoglobin by sodium nitrite and the effects of various substances on the oxidizing reaction were investigated. In the present paper, the effect of phenylhydrazine on the oxidation of oxyhaemoglobin was studied parallel with the haematological change. In the poisoned rabbits, the decrease of the red blood cells and the formation of Heinz-bodies were observed. At the same time, the oxidation rate of oxyhaemoglobin prepared from the poisoned rabbits was found to be notably reduced with increasing dose of the poison. The change of the oxidation rate was further ascertained by the experiments in vitro, although there were some differences between the results in vivo and in vitro.

The measurement of the oxidation rate of oxyhaemoglobin prepared from the blood of animals exposed to poisonous substances, which cause the blood changes, seems to be useful for the early detection of the poisoning.
\end{abstract}

As reported previously in this series,1) the oxidation rate of oxyhaemoglobin by sodium nitrite was considerably susceptible to the modification of haemoglobin molecule caused by some poisonous substances, such as formalin, p-chloromercuribenzoate, urea, nitroglycol and various medicaments. Modes of actions of these substances to the oxidation were classified into four types according to the different effects on the lag and the methaemoglobin forming phase.

This paper deals with the effect of phenylhydrazine on the oxidation of oxyhaemoglobin prepared from the blood of rabbits injected with phenylhydrazine which have been reported to cause the peripheral blood changes.2,3)

\section{Materials ANd Methods}

Male rabbits ranging in weight from 1.9 to $1.95 \mathrm{~kg}$ received subcutaneously 10-60 $\mathrm{mg}$ of phenylhydrazine per $\mathrm{kg}$ of body weight. Blood was punctured from the heart at $0.5,2,4,12,24$ and 48 hours after the injection.

Heinz-bodies and reticulocytes of the poisoned rabbits. Heinz-bodies and reticulocytes were counted using a microscope with an oil immersed lens after direct dying of the blood sample with an alcoholic solution of brilliant cresyl blue. The numbers of red blood cells containing Heinz-bodies were represent- 


\section{T. KAKIZAKI, M. SATO, H. TSURUTA AND H. HASEGAWA}

ed by the percentage in the counted 500 red cells.

Oxidation of oxyhaemoglobin by sodium nitrite. The heparinized blood obtained from the poisoned rabbits was washed and haemolyzed with deionized water. The supernatant haemoglobin solution was purified through a G-25 Sephadex column. The procedures in detail were described already.1)

The oxidation of oxyhaemoglobin was performed at the conditions of 0.05 $\mathrm{mM}$ oxhaemoglobin, $2.0 \mathrm{mM}$ sodium nitrite, $\mathrm{pH} 7.23$ and $25^{\circ} \mathrm{C}$. From the reaction curve, the time length of the lag phase $(\tau)$ and the rate of the methaemoglobin forming phase $(v)$ were measured as described in the previous paper.1,4)

Oxidation of oxyhaemoglobin by potassium ferricyanide. Clear oxyhaemoglobin solution obtained from the washed blood was used without the treatment by a Sephadex column. The oxidation of oxyhaemoglobin by potassium ferricyanide was carried out by adding $0.1 \mathrm{ml}$ of $6.2 \mathrm{mM}$-potassium ferricyanide solution to $3.0 \mathrm{ml}$ of $0.05 \mathrm{mM}$ oxyhaemoglobin solution at $\mathrm{pH} 7.23$ and $25^{\circ} \mathrm{C}$. The initial rate of the reaction was determined from the average slope of the reaction curve in three seconds after the beginning of the reaction and represented in terms of $\mu \mathrm{M}$ of methaemoglobin formed per second.

\section{Results}

\section{In Vivo Experiments}

Haematological changes in rabbits injected with phenylhydrazine

One of the outstanding effects of phenylhydrazine to men and animals has been reported to be haemolytic anemia with Heinz-body formation.2,3) In the poisoned rabbits, a severe decrease of the red blood cells and Heinz-body

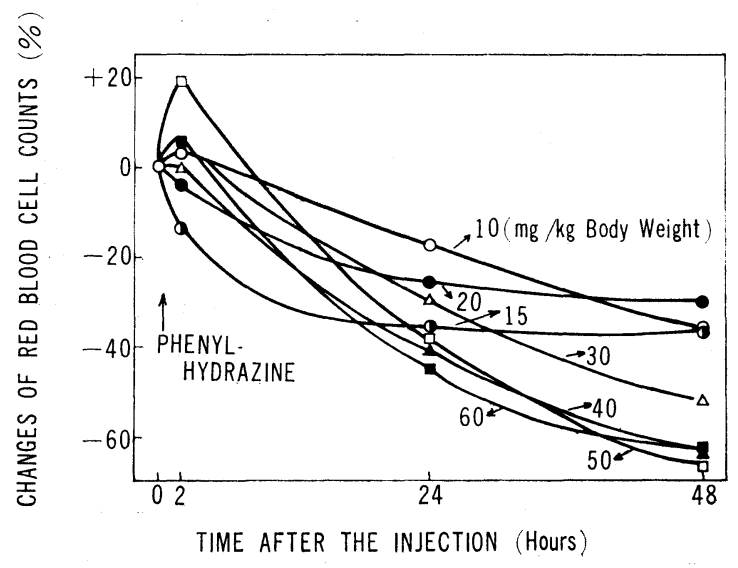

Fig. 1. Changes of red blood cell counts after the injection of phenylhydrazine.

Male rabbits received phenylhydrazine subcutaneously. The doses were indicated in the figure. The red blood cell counts after the injection were compared with those before the injection. 


\section{EFFECT OF PHENYLHYDRAZINE ON HAEMOGLOBIN OXIDATION}

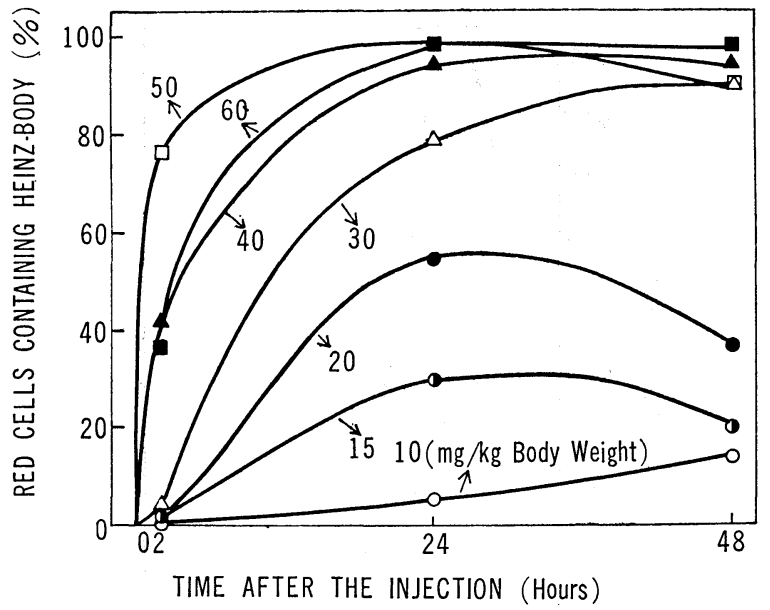

Fig. 2. Heinz-body formation by the injection of phenylhydrazine.

Ordinate: Percentages of red cells containing Heinz-bodies in 500 red cells.

formation were observed as shown in Figs. 1 and 2. These haematological changes reached to the maxima within about 24 hours, in some cases within 48 hours, after the dosage of phenylhydrazine. The decreasing rate of the red blood cells was nearly proportional to the amount of dose. This proportionality of haematological changes to the amount of dose was more clear in the formation of Heinz-bodies, although when the dose was over $40 \mathrm{mg} / \mathrm{kg}$, the rate of the formation was almost the same notwithstanding the increase of the dose.

Oxidation of oxyhaemoglobin from the phenylhydrazine poisoned rabbits by sodium nitrite

The purified oxyhaemoglobin solution prepared from the blood punctured at various times after the injection of phenylhydrazine was used for the oxidation by sodium nitrite. This oxyhaemoglobin solution was completely free from phenylhydrazine by Sephadex column treatment. From the reaction curve obtained, the time length of the lag phase, $\tau$ seconds, and the rate in the methaemoglobin forming phase, $v \mu \mathrm{M} /$ second, were estimated. The results were shown in Figs. 3 and 4 . As seen in the figures, $\tau$ values showed a remarkable increase with time after the injection of the poison, and $v$ values decreased. These changes of $\tau$ and $v$ reached to the maxima at 4 hours after the dosage, and then returned gradually toward the normal.

In Fig. 5, the maximum changes of $\tau$ and $v$ were plotted against the amount of the dose. Both $\tau$ and $v$ values were found to be proportional to the dose amounts.

A considerable interest was, as illustrated in Fig. 6, the relation between $\tau$ and $v$, that is, when $\tau$ became two times of the normal $(+100 \%$ change in ordinate), $v$ to a half ( $-50 \%$ change in abscissa). Although, as mentioned 


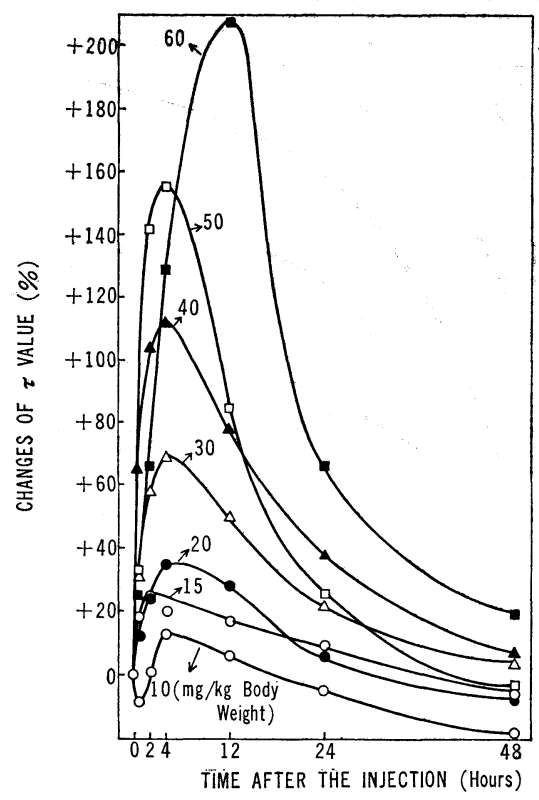

Fig. 3. Change of the period of the lag phase ( $\tau$ seconds) in the oxidation process of oxyhaemoglobin by sodium nitrite.

The oxidation of oxyhaemoglobin prepared from the rabbit blood punctured at various time intervals after the injection of phenylhydrazine was performed at the conditions of $0.05 \mathrm{mM}$ oxyhaemoglobin, $2.0 \mathrm{mM}$ sodium nitrite, $\mathrm{pH} 7.23$ and $25^{\circ} \mathrm{C}$.

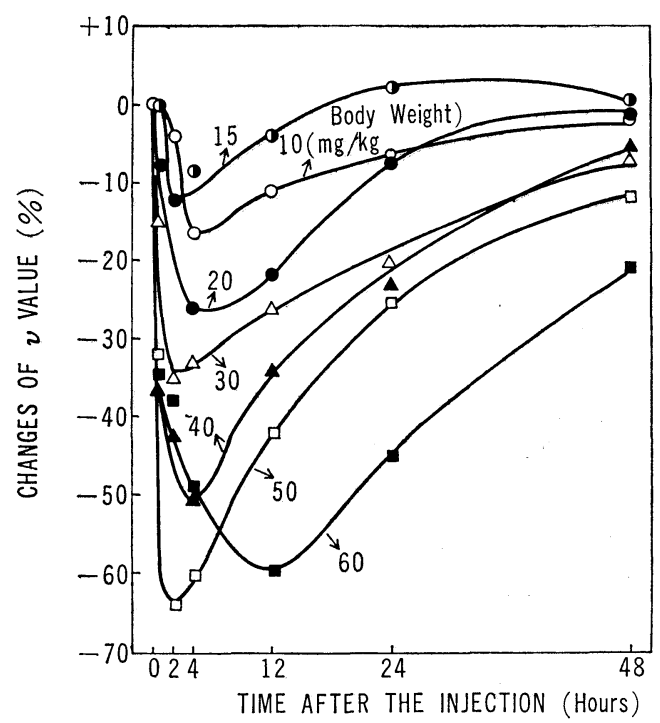

Fig. 4. Change of $v$ value in the oxidation of oxyhaemoglobin by sodium nitrite.

Experimental conditions for oxidizing oxyhaemoglobin were the same as those in Fig. 3. 


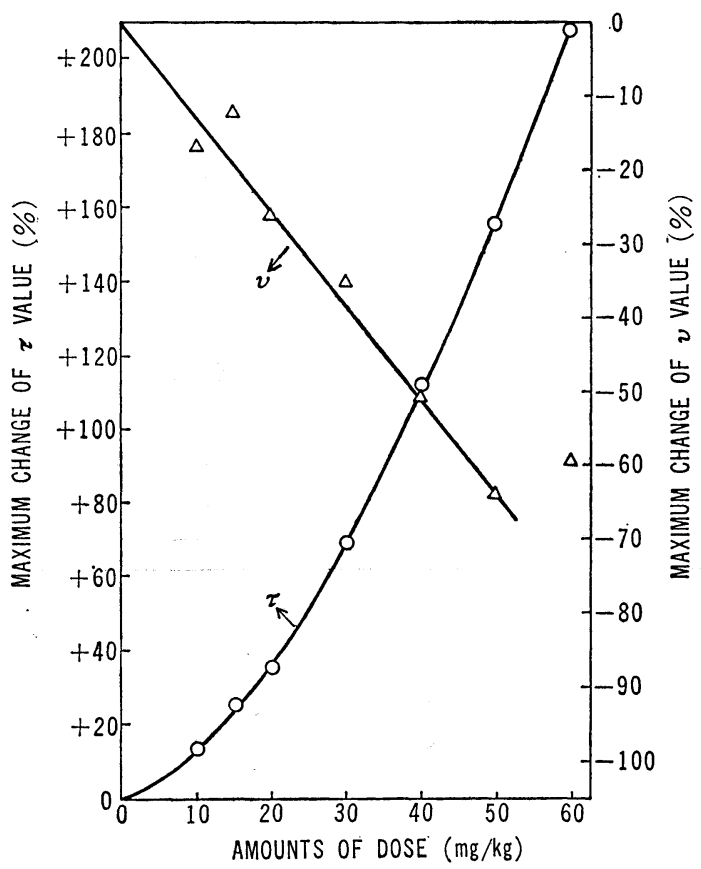

Fig. 5. Relationship between the dose of phenylhydrazine and the maximum change of $\tau$ or $v$ value.

The values of the maximum changes of $\tau$ or $v$ corresponding to various amounts of dose were obtained from the data indicated in Figs. 3 and 4.

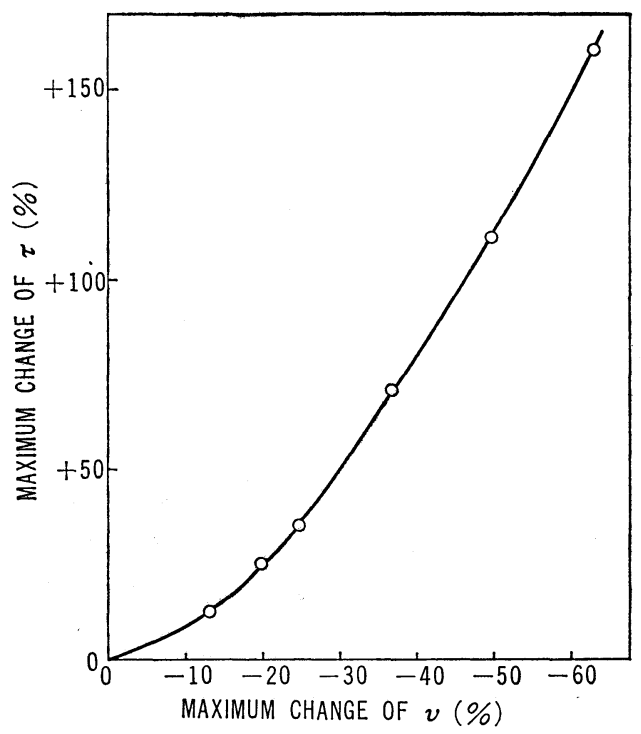

Fig. 6. Relationship between $\tau$ and $v$.

The data illustrated in Fig. 5 were used. 


\section{T. KAKIZAKI, M. SATO, H. TSURUTA AND H. HASEGAWA}

Table 1. Effect of phenylhydrazine injection on the oxidation rate of oxyhaemoglobin by potassium ferricyanide.

\begin{tabular}{c|c|c|c|c|c}
\hline $\begin{array}{c}\text { Dose amounts of } \\
\text { phenylhydrazine } \\
(\mathrm{mg} / \mathrm{kg})\end{array}$ & \multicolumn{5}{|c}{$\mu \mathrm{M}$ of methaemoglobin formed/second } \\
\cline { 2 - 6 } & $\begin{array}{c}\text { Before the } \\
\text { injection }\end{array}$ & 24 (hours) & 48 & 72 & 96 \\
\hline 5 & 5.25 & 5.69 & 4.61 & 5.12 & 5.23 \\
8 & 4.78 & 4.68 & 5.05 & 4.66 & 4.61 \\
12 & 5.05 & 5.30 & 5.39 & 5.80 & 4.82 \\
16 & 5.39 & 5.32 & 4.97 & 5.84 & 5.82 \\
20 & 5.08 & 5.43 & 5.32 & 5.39 & - \\
30 & 5.11 & 5.18 & - & - & - \\
40 & 5.13 & 5.27 & 4.85 & 5.07 & 5.08 \\
50 & 4.63 & 5.34 & 5.56 & 5.44 & 6.46 \\
60 & 5.04 & 5.37 & - & - & - \\
\hline
\end{tabular}

Oxidation of oxyhaemoglobin was carried out by adding $0.1 \mathrm{ml}$ of $6.2 \mathrm{mM}$ potassium ferricyanide solution to $3 \mathrm{ml}$ of $0.05 \mathrm{mM}$ oxyhaemoglobin solution at $\mathrm{pH} 7.23$ and $25^{\circ} \mathrm{C}$. The initial rate of the reaction was determined from the average slope of the reaction curve in three seconds after the beginning of the reaction.

above, a severe change of the oxidation rate of oxyhaemoglobin by sodium nitrite was observed, the rate of oxidation by potassium ferricyanide, which acts directly on the haem part, showed no appreciable change as indicated in Table 1. These facts may suggest that phenylhydrazine acts on the protein part of oxyhaemoglobin molecule resulting in the intramolecular structure modification, which did not affect the properties of the haem parts but on the nitrite affinity of oxyhaemoglobin.

\section{In Vitro Experiments}

Effect of phenylhydrazine on the oxidation rate by sodium nitrite in vitro

Purified oxyhaemoglobin solution $(0.05 \mathrm{mM})$ prepared from normal rabbits was incubated with various concentrations of phenylhydrazine solution for 5 minutes at $25^{\circ} \mathrm{C}$ and $\mathrm{pH} 7.23$ (M/75-phosphate buffer). To $2 \mathrm{ml}$ of the incubated oxyhaemoglobin solution containing phenylhydrazine, $1 \mathrm{ml}$ of sodium nitrite solution $(2 \mathrm{mM})$ was added. The values of $\tau$ and $v$ thus obtained were shown in Fig. 7. As seen in the figure, $v$ values reduced linearly with increasing concentration of the poison, while $\tau$ values showed a complex behavior with the reduction in low concentrations of phenylhydrazine and the increase in high concentrations. Thus, the relation between $\tau$ and $v$ in vitro showed a little difference from that in vivo experiments.

Since the reduction of $\tau$ in vitro experiments was most remarkable in the presence of $10 \mu \mathrm{M}$ phenylhydrazine, the changes of $\tau$ and $v$ with time were studied at this concentration of the poison. As seen in Fig. 8, the values of $\tau$ and $v$ showed a sharp decrease immediately after mixing the oxyhaemo- 


\section{EFFECT OF PHENYLHYDRAZINE ON HAEMOGLOBIN OXIDATION}

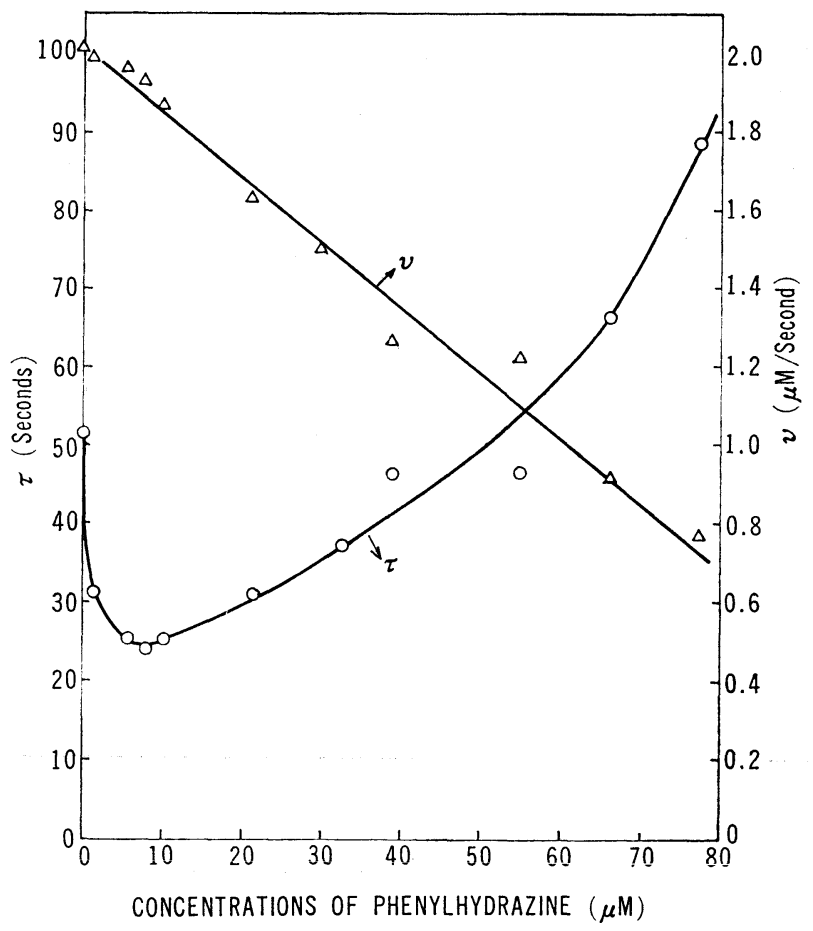

Fig. 7. Oxidation of oxyhaemoglobin incubated with phenylhydrazine by sodium nitrite.

Purified oxyhaemoglobin solution prepared from the blood of normal rabbits was incubated with various concentrations of phenylhydrazine for 5 minutes at $25^{\circ} \mathrm{C}$ and $\mathrm{pH}$ 7.23. The oxidation of oxyhaemoglobin by sodium nitrite was carried out at the conditions of $0.05 \mathrm{mM}$ oxyhaemoglobin containing phenylhydrazine, $2.0 \mathrm{mM}$ sodium nitrite, $\mathrm{pH} 7.23$ and $25^{\circ} \mathrm{C}$.

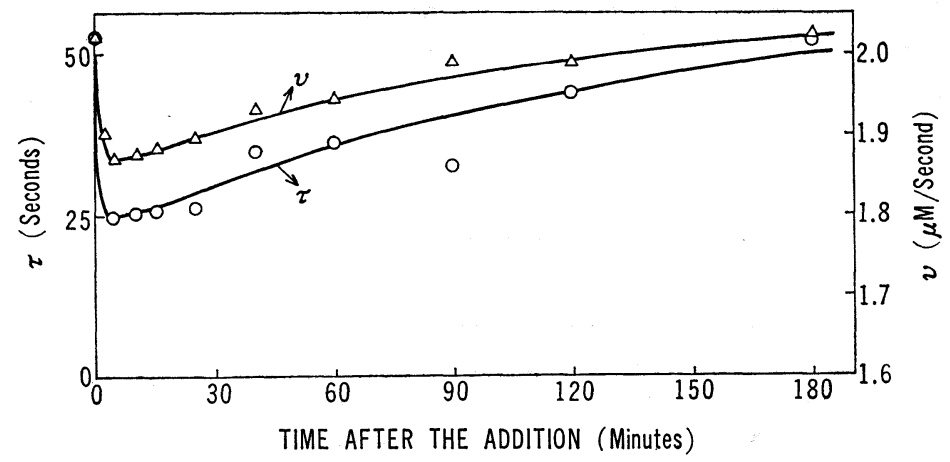

Fig. 8. Change of oxidation rate of oxyhaemoglobin by sodium nitrite after the addition of phenylhydrazine.

At various time intervals after mixing oxyhaemoglobin and $10 \mu \mathrm{M}$ phenylhydrazine at $\mathrm{pH} 7.23$ and $25^{\circ} \mathrm{C}$, the oxidation of oxyhaemoglobin by sodium nitrite was performed; oxyhaemoglobin concentration: $0.05 \mathrm{mM}$, sodium nitrite: $2.0 \mathrm{mM}$, $\mathrm{pH} 7.23,25^{\circ} \mathrm{C}$. 


\section{T. KAKIZAKI, M. SATO, H. TSURUTA AND H. HASEGAWA}

globin solution and phenylhydrazine, and after 5 minutes they returned toward the control values. This process corresponded well with that of the optical density change of oxyhaemoglobin at $578 \mathrm{~m} \mu$, or that of cyanmethaemoglobin at $540 \mathrm{~m} \mu$ as indicated in Table 2. Since, at $500-600 \mathrm{~m} \mu, 10 \mu \mathrm{M}$ of phenylhydrazine does not show any light absorption ( $\varepsilon \mathrm{mM}$ at $\left.550 \mathrm{~m} \mu=3.5 \times 10^{-6}\right)$, the optical density change in Table 2 may indicate an intramolecular structure change of oxyhaemoglobin molecule caused by phenylhydrazine, and the recovery of the oxidation rate or of optical density may indicate the decomposition of phenylhydrazine molecule into an inactive form for oxyhaemoglobin molecule, that is, the intramolecular structure change seems to be reversible. Furthermore, as illustrated in Table 3, when pure phenylhydrazine was exposed to the air, its optical density at $450 \mathrm{~m} \mu$ increased gradually.

Table 2. Optical density change of oxyhaemoglobin by the addition of phenylhydrazine.

\begin{tabular}{c|c|c}
\hline $\begin{array}{c}\text { Time after the } \\
\text { addition of phenyl- } \\
\text { hydrazine } \\
\text { (minutes) }\end{array}$ & $\begin{array}{c}\varepsilon \mathrm{mM} \text { at } 578 \mathrm{~m} \mu \\
\text { of } \\
\text { oxyhaemoglobin }\end{array}$ & $\begin{array}{c}\varepsilon \mathrm{mM} \text { at } 540 \mathrm{~m} \mu \\
\text { of } \\
\text { cyanmethaemoglobin }\end{array}$ \\
\hline 0 & 15.0 & 11.4 \\
1 & 12.0 & 9.1 \\
2 & 12.1 & 9.4 \\
5 & 11.8 & 9.2 \\
10 & 11.9 & 9.3 \\
70 & 13.8 & 11.1 \\
180 & 14.1 & 11.1 \\
\hline
\end{tabular}

After mixing $0.05 \mathrm{mM}$ oxyhaemoglobin and $10 \mu \mathrm{M}$ phenylhydrazine at $\mathrm{pH}$ 7.23 and $25^{\circ} \mathrm{C}$, the optical density change at $578 \mathrm{~m} \mu$ was followed. At the same time, the optical density of cyanmethaemoglobin produced by adding potassium ferricyanide and cyanide to the above oxyhaemoglobin solution was measured at $540 \mathrm{~m} \mu$.

Table 3. Decomposition of phenylhydrazine in air.

\begin{tabular}{c|c}
\hline $\begin{array}{c}\text { Time } \\
\text { (minutes) }\end{array}$ & $\begin{array}{c}\text { Optical density } \\
\text { at } 450 \mathrm{~m} \mu\end{array}$ \\
\hline 0 & 0.330 \\
30 & 0.465 \\
60 & 0.540 \\
120 & 0.650 \\
180 & 0.705 \\
\hline
\end{tabular}

Pure phenylhydrazine was exposed to air at $25^{\circ} \mathrm{C}$ and its optical density change, which may be due to the decomposition of phenylhydrazine, was followed at $450 \mathrm{~m} \mu$. 


\section{EFFECT OF PHENYLHYDRAZINE ON HAEMOGLOBIN OXIDATION}

\section{Discussion}

These in vitro experiments on the oxidation rate of oxyhaemoglobin by sodium nitrite showed that the intramolecular structure change of haemoglobin produced by phenylhydrazine seemed to be reversible. From the in vivo experiments, on the other hand, the changes of $\tau$ and $v$ were recognized to be the result of the irreversible intramolecular structure change because oxyhaemoglobin was used after removing off free phenylhydrazine by Sephadex column treatment. The discrepancy between in vivo and in vitro experiments may be explained as follows; If a rabbit of $2 \mathrm{~kg}$ body weight contains $200 \mathrm{ml}$ of blood in the body and if all of phenylhydrazine injected subcutaneously penetrates into the blood, the dose, $10 \mathrm{mg}$ of phenylhydrazine per $\mathrm{kg}$ body weight, corresponds to $1 \mathrm{mM}$ phenylhydrazine in the blood. Such a high concentration of the poison was not used for in vitro experiments in this paper. If, therefore, phenylhydrazine in high concentrations beyond $100 \mu \mathrm{M}$ was used, and if the oxidation by sodium nitrite was performed after incubating for 3 hours, an irreversible change of oxyhaemoglobin molecule might be observed.

The irreversible change of oxyhaemoglobin molecule caused by phenylhydrazine seems to obstruct the combination of nitrite ions to the protein moiety of oxyhaemoglobin molecule because $\tau$ value increased inversely with the decrease of $v$ value. In the previous paper,4) it was found that the oxidation process was represented as follows; in the lag phase

$$
\begin{aligned}
& \mathrm{Hb}\left(\mathrm{O}_{2}\right)_{4}+2 \mathrm{NO}_{2}^{-} \rightleftarrows \mathrm{Hb}\left(\mathrm{O}_{2}\right)_{4}\left(\mathrm{NO}_{2}\right)_{2} \\
& \mathrm{Hb}\left(\mathrm{O}_{2}\right)_{4}\left(\mathrm{NO}_{2}\right)_{2} \longrightarrow \mathrm{Hb}^{\prime}\left(\mathrm{O}_{2}\right)_{4}\left(\mathrm{NO}_{2}\right)_{2}
\end{aligned}
$$

and in the methaemoglobin forming phase

$$
\begin{aligned}
& \mathrm{Hb}^{\prime}\left(\mathrm{O}_{2}\right)_{4}\left(\mathrm{NO}_{2}\right)_{2}+\mathrm{NO}_{2}^{-}+1 / 2 \mathrm{H}_{2} \mathrm{O} \longrightarrow \mathrm{Hb}^{\prime}\left(\mathrm{O}_{2}\right)_{3}(\mathrm{OH})\left(\mathrm{NO}_{2}\right)_{2}+\mathrm{NO}_{3}^{-} \\
&+1 / 4 \mathrm{O}_{2} \\
& \mathrm{Hb}^{\prime}\left(\mathrm{O}_{2}\right)_{3}(\mathrm{OH})\left(\mathrm{NO}_{2}\right)_{2}+\mathrm{NO}_{2}^{-}+1 / 2 \mathrm{H} \mathrm{O} \longrightarrow \mathrm{Hb}^{\prime}\left(\mathrm{O}_{2}\right)_{2}(\mathrm{OH})_{2}\left(\mathrm{NO}_{2}\right)_{2} \\
&+\mathrm{NO}_{3}^{-}+1 / 4 \mathrm{O}_{2} \\
& \mathrm{Hb}^{\prime}\left(\mathrm{O}_{2}\right)_{2}(\mathrm{OH})_{2}\left(\mathrm{NO}_{2}\right)_{2}+\mathrm{H}_{2} \mathrm{O} \longrightarrow \mathrm{Hb}(\mathrm{OH})_{4}+2 \mathrm{NO}_{3}^{-}+1 / 2 \mathrm{O}_{2}
\end{aligned}
$$

In these consecutive reactions, if the combining reaction of nitrite ions to modified oxyhaemoglobin caused by phenylhydrazine, reactions (1), (3) and (4), did not proceed enough rapidly comparing with the normal oxyhaemoglobin, the increase of $\tau$ and the decrease of $v$ would take place.

The oxidation of oxyhaemoglobin by sodium nitrite was proved to be very sensitive to a slight modification of the protein structure of oxyhaemoglobin. The method in this paper, therefore, should be useful for the early detection of the poisoned blood. 
T. KAKIZAKI, M. SATO, H. TSURUTA AND H. HASEGAWA

\section{ReFERENCES}

1) Kakizaki, T., Sato, M., Tsuruta, H. and Hasegawa, H. (1964). Ind. Health, 2, 139.

2) von Oettingen, W. F. (1941). U. S. Public Health Bull., No. 271, 158.

3) Sutton, W. L. (1963). Industrial Hygiene and Toxicology (Edited by Patty, F. A.), Vol. 2, p. 2227. Interscience Publishers, New York.

4) Kakizaki, T., Sato, M., Tsuruta, H. and Hasegawa, H. (1965). J. Japan. Biochem. Soc., 37, 14. (in Japanese). 